\title{
Comparison of Bone Mineral Density between Professional Cyclists of Union Europe International and Non-athletes
}

\author{
Shabani Mohammad \\ Assistant Professor, Kashmar Higher Education Institute \\ Kashmar, Iarn \\ rs_shabani@yahoo.com
}

Balaghi Zivar

Msc students, Islamic Azad University, Bojnord Branch Bojnord, Iran

Talebi Maryam

Msc students, Islamic Azad University, Bojnord Branch Bojnord, Iran

\author{
Mazani Ali Asghar \\ Phd students, Sabzevari Hakim University \\ Sabzevar, Iran \\ Mazani1351@yahoo.com
}

Niyazi Toktam

Msc students, Islamic Azad University, Bojnord Branch Bojnord, Iran

\section{Shirazi Nassim}

Msc students, Islamic Azad University, Bojnord Branch Bojnord, Iran

\begin{abstract}
The purpose of this study was to compare the Bone Mineral Density (BMD) of lower and upper limbs between professional cyclists of Union Europe International and nonathletes. In this research 73 professional cyclists of Union Europe International (UEI) and 32 non-athletes were participated. The BMD of lower and upper limbs were measured by DEXA. The collected data were analyzed through t-test statistical methods $(\mathrm{p} \leq 0 / 05)$ using software of Statview 5. The results showed that BMD of lower and upper limbs was difference between the two groups, the professional cyclists having lower values (except head and arms). The results of researches showed that the physical exercises may not have a generalized effect on the skeleton and the sport of cycling not provides an osteogenic stimulus for bone.
\end{abstract}

\section{Keywords- Bone Mineral Density; professional cyclists}

\section{INTRODUCTION}

Low bone mineral density (BMD) is a serious public health problem. The results of researches showed that osteoporotic fractures are associated with bone tissue, occurring frequently in the spine and hip.

Numerous studies have reported that bone mineral density (BMD) is higher in those who exercise as compared to sedentary individuals and thus, exercise is often recommended to prevent osteoporosis. Whereas the studies have shown that different types of exercise cause different effects on bone remodelling. The most researches have been suggested that the physical activity increases bone formation and then BMD. On the other hands, the weight- bearing activity is essential to obtain beneficial skeletal effects on total and regional bone mass. In fact, the studies have demonstrated a positive relationship between bone mineral density and weight bearing exercise. While the other Studies have shown that non-weightbearing activities such as cycling have not been reported to display this positive relationship between exercise and BMD [1]. In fact, the biomechanical nature of cycling involves high pedalling frequency with generally low forces and very minimal, if any, impact.

From a public health point of view, cycling is a widely practiced non-weight-bearing exercise around the world, and the bicycle is also used by millions of people in many different countries, accounting for an important part of their daily physical activity.

Cycling usually consider to be a highly beneficial activity for increasing cardiovascular fitness in human, yet researches showed little or no corresponding improvements in bone tissue [2]. On the other hands, the important question was the cycling is an aerobic endurance activity that is beneficial for cardiovascular health, but is it beneficial to the skeletal system? The hypothesis of present study was that cycling would have little or no effect on BMD of lower and upper limbs. This was tested by comparing professional cyclists of Union Europe International and non-athletes.

\section{MATERIALS AND METHODS}

A total of 105 subjects were recruited to participate in present study, including 73 professional cyclists of Union Europe International (UEI) (age: 25/81 $\pm 4 / 35$ years, height: $179 / 66 \pm 6 / 31 \mathrm{~cm}$, weight: $71 / 55 \pm 6 / 31 \mathrm{~kg}$ ) and 32 nonathletes (age: $28 / 28 \pm 4 / 52$ years, height: $176 / 56 \pm 6 / 2 \mathrm{~cm}$, weight: $74 / 47 \pm 8 / 35 \mathrm{~kg}$ ). On the average, cyclists had been training competitively for more than 10 years. All cyclists had 
competition experience of at least 2 years in the professional category of the UEI, were used in a licensed professional team, and had participated in at least 1 of the main 3 week stage races (Giro d'Italia, Tour de France or Vuelta a Espana).

The BMD of lower and upper limbs were measured by DEXA (dual-energy X-ray absorptiometry). The collected data were analyzed through t-test statistical methods $(p \leq 0 / 05)$ using software of Statview 5, SAS Institute Inc, USA.

\section{RESULTS}

Table 1 shows the comparison of BMD of lower and upper limbs between cyclists and non-athletes. The results showed that BMD of lower and upper limbs was difference between the two groups, the professional cyclists having lower values (except head and arms).

Table 1: Comparison of BMD of lower and upper limbs between cyclists and non-athletes.

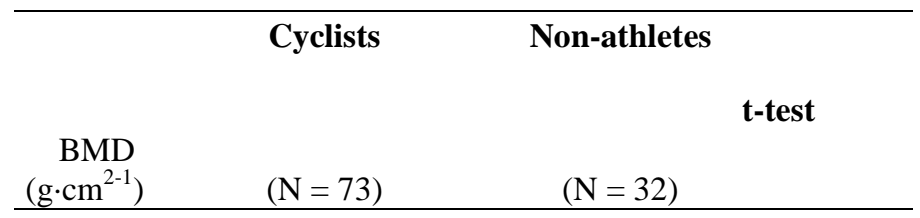

\begin{tabular}{|c|c|c|c|}
\hline Head & $2 / 04 \pm 0 / 20$ & $2 / 10 \pm 0 / 23$ & NS \\
\hline Arms & $0 / 93 \pm 0 / 07$ & $0 / 95 \pm 0 / 08$ & NS \\
\hline Legs & $1 / 37 \pm 0 / 13$ & $1 / 48 \pm 0 / 14$ & $\mathrm{P}=0 / 001$ \\
\hline Ribs & $0 / 68 \pm 0 / 05$ & $0 / 72 \pm 0 / 06$ & $\mathrm{P}=0 / 001$ \\
\hline Pelvis & $1 / 11 \pm 0 / 11$ & $1 / 25 \pm 0 / 14$ & $\mathrm{P}=0 / 0001$ \\
\hline Spine & $1 / 00 \pm 0 / 13$ & $1 / 11 \pm 0 / 14$ & $\mathrm{P}=0 / 001$ \\
\hline Total & $1 / 18 \pm 0 / 08$ & $1 / 25 \pm 0 / 10$ & $\mathrm{P}=0 / 0001$ \\
\hline
\end{tabular}

\section{DISCUSSION}

The influences of physical activity, exercise and mechanical loading on the bone tissue have been extensively researched in both animals and humans. In humans, the effect of exercise type on bone adaptations has been inferred mostly from cross- sectional studies of athletes from different sports, compared with nonathlete controls.

Few studies have investigated bone mineral density in professional cyclists. The present data indicate that the professional cyclists have abnormally low values of their bone mineral density. Our findings agree with those reported by Medelli et al [3] and Campion et al [4] showing that elite and professional road cyclists had lower total and regional BMD than a control group. The result of another study by Medelli et al showed that two-thirds of professional cyclists had abnormally low BMD values [5].The researcher of Nichols et al also indicated that the high percentage of male master cyclists with low BMD, combined with a high risk for fracture from falls associated with competitive cycling, warrant attention among this population [6]. In contrast, Warner et al found that BMD in the mountain cyclists was higher than road cyclists, thus, that mountain cycling may provide an osteogenic stimulus that is not inherent to road cycling [7].

The results of researches showed that the physical exercises may not have a generalized effect on the skeleton. In fact, exercise loads affecting the skeleton can vary in many ways according to the different sports practised; the difference depends mainly on the intensity and direction of the forces which apply to the skeleton [8].

In conclusion, the results of present study suggest that the sport of cycling not provides an osteogenic stimulus for bone. In fact, the cyclists may be at risk for low bone mass, particularly at the legs, lumbar spine and whole body. On the other hand, from our comprehensive survey of the current study we can be concluded that cycling does not appear to confer any significant osteogenic benefit. The cause of this may be related to spending long hours ( 3 to 5 hours per day) in a weightsupported position on the bike in combination with the necessary enforced recovery time that involves a large amount of time sitting or lying supine, especially at the competitive level.

Thus, health professionals and coaches interacting with professional cyclists need to promote alternative activity such as plyometric, running, or other high impact exercise as a complement to cycle training to help minimize bone loss in these athletes. It is necessary to pay greater attention to the bone status of professional cyclists to prevent an increased risk of fractures.

\section{REFERENCES}

[1] Medelli J, Campion F, Shabani M, Lounana J, Cordero-Maclntyre Z. Why do competition road cyclists have a low bone mineral status? International Journal of Body Composition Research, 2010 Vol.8, Supplement: S83-91.

[2] Olmedillas H, González-Agüero A, Moreno LA, Casajus JA, VicenteRodríguez G.Cycling and bone health: a systematic review. BMC Med. 2012; 20;10:168.

[3] Medelli J, Shabani M, Lounana J, Fardellone P, Campion F. Low bone mineral density and calcium intake in elite cyclists. J Sports Med Phys Fitness 2009; 49: 44 - 53.

[4] Campion F, Nevill AM, Karlsson MK, Lounana J, Shabani M, Fardellone P, Medelli J. Bone Status in Professional Cyclists. Int J Sports Med 2010; 31:511- 515. 
[5] Medelli J, Lounana J, Menuet JJ, Shabani M, Cordero-MacIntyre Z. Is osteopenia a health risk in professional cyclists? J Clin Densitom. 2009; 12(1):28-34.

[6] Nichols JF, Rauh MJ. Longitudinal changes in bone mineral density in male master cyclists and no athletes. J Strength Cond Res. 2011; 25(3):727-34.

[7] Warner SE, Shaw JM, Dalsky GP. Bone mineral density of competitive male mountain and road cyclists. Bone. 2002; 30(1):281-6.

[8] Heinonen A. et at. Bone mineral density of female athletes in different sports. Bone Mm., 23, 1, 1993. 